\title{
Structural Variations of Adjective in English and Okpameri
}

\author{
Raifu O. Farinde \\ Department of English and Literary Studies, Federal University Oye-Ekiti, Ekiti State, Nigeria \\ Happy O. Omolaiye \\ Department of General Studies, The Federal Polytechnic, Ile-Oluji, Ondo State, Nigeria
}

\begin{abstract}
Adjectives indicate grammatical property of language. They give more information about nouns. The usage of adjective in utterances varies in languages. These variations often pose problem to ESL learners. Predicating on Contrastive Analysis, the study generated Okpameri data from oral sources and participatory observation. English data were got from the English grammar texts. From the findings, the two languages are grammatically marked for pre/post modifying adjective, predicative adjective, degree of adjective and order of adjective. However, the grammatical structure and usage of these adjectives differ. While English adjectives often pre-modify the headword, Okpameri adjectives usually post-modify the headword. Also, while English distinguishes between the use of "beautiful" and handsome for feminine and masculine genders respectively, Okpameri language resorts to using uni-gender "shemilushe" which its equivalent translation in English is either "beautiful or handsome". As in the case of degree of adjective, suffixes are attached to the root-word to form comparative and superlative adjectives of the two languages. It has been observed that English adjectival pre-modification is consistent. However, Okpameri adjectives function as pre/post-modifiers. The study, therefore suggests that language teachers, particularly English language experts, should adopt systematic approach to the teaching of adjectives as this will broaden the knowledge of Okpameri ESL learners.
\end{abstract}

Index Terms - English, Okpameri, adjective, second language, grammar

\section{INTRODUCTION}

Structural variation of language is usually occasioned by difference in culture. Thus, culture becomes one of the determining factors of language structure. Every language structure is the carrier of the culture that produces the language. For instance, the structure of English adjectives might seem not to be the same with the structure of Okpameri adjectives because of cultural differences. Since English is the target language, it therefore becomes pertinent to view the structure of the Okpameri adjectives on the structure of the English adjective as this will reveal the areas of similarities and differences. The differences of the two languages under study will definitely improve on the teaching of adjective in ESL context.

What actually informed this study is borne out of the fact that Okpameri language is yet to receive much scientific study, particularly, in the area of grammatical structure. Beaming searchlight on the identified problem area(s), the present study will reveal the likely problem the study of the English adjectives will pose to Okpameri ESL learners in the course of learning the English adjectives. The likely problem predicted will definitely go a long way in improving on the teaching methodology of the English adjectives.

As earlier mentioned, Okpameri language is yet to receive much scientific study. In other words, scholars have not really researched on the language. It must be stated here that language not scientifically studied might go into extinction. Hence, the study of the structure of Adjectives in English and Okpameri becomes significant.

Okpameri language is one of the Edoid languages (see Elugbe, 1989, Damola, 2004, Omolaiye, 2017, etc). According to Elugbe (1989), all the languages (such as Okpameri) that have generic resemblance must have descended from a common photo-language as it were and of which each had later emerged as a distinct language over a long period of time. The linguistic affinity among the Okpameri is one the greatest evidence of their oneness as a people. This explains why the word "Okpameri" means "we are one".

In the works of Hakeem (2003) and Ekharo et al (2007), Okpameri is classified as belonging to North-Western Edoid community who had retained its Edoid language and speaks a heavily accented variety of Yoruba as a second language. Okpameri is in Akoko-Edo Local Government Area of Edo State. The communities that make up Okpameri in the Local government are located in almost all the political constituencies in the said local government. Hence, the following communities are in Akoko-Edo North constituency: "Lampese", "Bekuma", "Ibillo", "Imoga", "Ekpesa", "Ekor", "the Ikirans" "the Ugboshis", "Aiyegunle", "Ogugu", and "Somonka", while communities like "Ojirami", "Dangbala", "Ojah", "Makeke", "Ekpe" are in Akoko-Edo South constituency. Okpameri is a language widely spoken in the local government, and it has population of about 62,000 (Omolaiye, 2013:5 citing population census of 2006 in Edo State). 
The people are predominantly farmers. A sizable number of the female population are gari producers while some trade with the nearby villages and towns (in Kogi state), and Igarra (in Akoko-Edo, Edo State). Communities like "Ugboshi", "Ikiran", "Ibillo", "Ekpesa", "Lampese", "Bekuma”, "Makeke” and "Ekpe” fairly speak Yoruba and Ibira languages as the communities share common boundary with Yoruba and Ibira town and villages.

As earlier stated, this paper is out to investigate structural variations of the English and Okpameri adjectives. However, emphasis will be on pre/post modifying adjectives, predicative adjectives, degree of adjective and order of adjective.

In a research work of this nature, it is paramount to briefly discuss some related terms of adjectives of the two languages under study as this will enhance the theoretical base of discussion. The discussion thus, begins with pre/post modifying adjectives.

Grammarians simply define adjectives as words used to modify or give more information about nouns or pronouns. (see Farinde \& Ojo, 1998, Murthy, 2007, Jimoh 2009, Ojo 2011, Oyelekan 2002 etc.). By implication, any word used to describe, modify or qualify a noun is referred to as an adjective. However, words are not discriminately used as adjectives. They are used in line with the dictates of the grammar of a language. For instance, it is ungrammatical to render the English expression thus: "beautiful two ladies" instead of "two beautiful ladies". It is also wrong to say "grammar errors instead of "grammatical errors" in English. Adjectives are functionally classified as:

-Attributive: directly attached to a nominal item to function as a pre-modifier or post modifier e.g beautiful lady, the president elect etc.

-Predicative: Coming after the verb of a given sentence e.g He is fine, Don't be foolish etc.

-Numerical: Usually marked by cardinal numerals or ordinal numerials e.g. five houses, first speaker etc.

-Interrogative: used as a pre-modifier to ask questions e.g whose name is written?; which state that is free of coronal virus? etc.

-Demonstrative: used as a pre-modifier to point at something or somebody e.g. This book is standard; those students are very brilliant etc.

-Possessive: used as a pre-modifier to indicate possession e.g. my book; your house etc.

-Nominal: a noun used as a pre-modifier to perform the function of adjective e.g Nigeria police; town crier etc.

-Proper noun: a proper noun inflected to perform the function of an adjective e.g European countries; a Ghananian citizen etc.

-Verbal: Participles used as pre-modifiers to perform the function of an adjective e.g reading book; spoken English etc.

-The Articles: used as a pre-modifiers to perform the function of an adjective. Articles are used for specific and nonspecific referent. Specific referent: the man. The non-specific: $\underline{a}$ girl, an empty space etc.

-The determinants: used as a pre-modifier or post modifier to perform the function of an adjective. Determinants are used to talk about the quantity of things or humans e.g few people attended the meeting, little milk is good for you etc.

-Emphasizing words: As the name suggests, they are words used as modifiers to perform the function of adjectives. They are usually used to emphasize nouns e.g I saw my very sister in the party. It is my own money I used to build the house etc.

-Exclamatory word: used as an adjective to express one's feeling e.g what! a beauty, what! an insult, etc.

The English adjectives are also used for comparison. In essence, comparison of adjectives has to do with expressing adjectives in terms of grading, that is, deriving their comparative and superlative forms. When two things or people are compared, the comparative form of adjective is used, while superlative form is used when more than two items or people are compared. This implies that adjectives and particularly, the traditional adjectives are inflected for comparative and superlative forms. Most monosyllabic adjectives usually derive their comparative and superlative forms with the addition of the morpheme "er" and "est" respectively. Consider the following:

big - bigger - biggest

tall - taller - tallest

fat - fatter - fattest

According to Oyelekan (2002), some di-syllabic adjectives do take either "er" and "est" or "more" and "most" for their comparative and superlative forms. Some of these examples are:

happy - happier - happiest

heavy - heavier - heaviest

lay - lazier - laziest

active $-\underline{\text { more }}$ active $-\underline{\text { most }}$ active

Some of the multi-syllabic adjectives also take "more" and 'most' as their comparative and superlative forms. They are:

beautiful - $\underline{\text { more }}$ beautiful $-\underline{\text { most }}$ beautiful, palatable $-\underline{\text { more }}$ palatable $-\underline{\text { most }}$ palatable

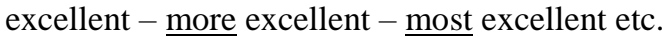

It must be mentioned here that some adjectives do not have fixed rules to form their comparative and superlative forms. Murthy (2007) refers to them as "irregular comparative and superlative adjectives". Some of these irregular adjectives are: 
good - better - best, bad - worse-worst, much - more - most, little - less - least.

As earlier mentioned, when more than one adjective pre-modifies a particular noun, there is an order they usually follow so as to have a grammatical and meaningful arrangement (see Ashaolu, et al 1995). In other words, pre-modifiers do not follow one another indiscriminately. Using the mnemonic as preferences for adjectival word-order, Ojo (2011) states as follows:

-Number (N) e.g one, six, third, fifth etc.

-Attributes (A) e.g. beautiful, ugly, elegant, poor, rich, experience, extravagant etc.

-Size/weight (s/w) e.g. tall, short, big, large, small, little, heavy, light etc.

-Age (A) e.g. new, young, old, modern, ancient, archaic, obsolete, outdated, old-fashioned etc.

-Shape (S) e.g. fat, thin, lanky, stout, slim, round, circular, rectangular, oblong etc.

-Colour (C) e.g. red, white, black, dark, yellow, dark-skinned, fair-skinned, light, fair blonds etc.

-Nationality/Origin (N/O) e.g. Nigerian, Italian, Japanese, Ghanaian, American etc.

-Nouns used as adjectives $(\mathrm{N})$ e.g. leather, silk, sports, cotton, metal etc.

The above mnemonic is written in adjectival order of occurrence in a sentence. It must be stated here that not all the above adjectives might occur in a particular nominal group. Therefore, correct use of adjectives enhances linguistic competence.

\section{The Okpameri Adjectives}

Okpameri has adjectives in its grammar. That is, certain words are used to modify or describe nouns in Okpameri utterances. Similar to English, words are not discriminately used as adjectives in Okpameri language. Their usage also goes along with the dictates of the grammar of the language. It is an error to say n'eva (two) Ivbia (children) instead of Ivbia (children) n'eva (two).

Just as the English adjectives are classified functionally, Okpameri adjectives could also be classified as:

-Attributive: directly attached to a nominal item to function as a post modifier e.g. Ozha n'oshemushe (wife beautiful), omọ-o shemi (child good) etc.

-Predicative: lopping together the be-verb with adjectival word to function as predicative adjective, e.g. Ojo-o nẹzugueh (Ojo-he intelligent); O she (she tall) etc.

-Numerical: usually marked by cordinal numerals or ordinal numerials e.g Izili-ẹ n'esa (goats-they three), Uguẹh Okhenikeh (thing first) etc.

-Interrogative: used as post-modifier to ask questions, thus performs the function of adjective e.g. Iweh egu? (book

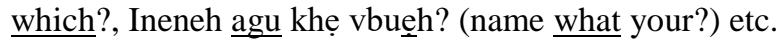

-Demonstrative: used as post-modifier to point at something or somebody e.g. Omọ nọ (child this), Avbua amọh (dog that) etc.

-Possessive: used as a post-modifier to indicate possession. eg. Eguo amẹh (shirt my), ozha mẹh (wife my) etc.

-Nominal: noun used as post-modifier to perform the function of adjective e.g Onyo Okpameri (indigene Okpameri), police-e inigeria (police-they Nigeria) etc.

-The Article: used as post-modifier to perform the function of adjective e.g. Ibo-ẹ weni (people-they the), ọmọhọzi-ọ weni (boy-he the) etc. Note: Okpameri language does not mark for indefinite articles.

-The determinants: used as pre-modifier to perform the function of adjective e.g ito agbọ (few people).

-Emphatic: used as post modifier to perform the function of adjective e.g Ukpo mẹh kpa (house my own), ọmọ mẹh kpa (child my own).

-Exclamatory word: used as an adjective to express inner feelings of the speaker e.g. uka kunoh! (shame, a what!), Asẹkhẹ kanoh! (mence a what!) etc.

Just as the English adjectives are used for comparison, Okpameri adjectives are also used for grading. Hence, Okpameri adjectives have comparative and superlative forms. Some of the examples are:

\begin{tabular}{llll} 
- & Kheke & - khekevene & - khekevha \\
(small & \multicolumn{1}{c}{ smaller } & smallest) \\
- & Khọi & - khọivene & - Khọivha \\
(big & - bigger & - biggest) \\
- & fiea & - fieavene & - fieavha \\
(loud & - louder - loudest)
\end{tabular}

It is pertinent to state that all Okpameri degree of adjectives are regular in form unlike English that some degree of adjective are irregular in form.

Consider:

\begin{tabular}{|c|c|c|c|}
\hline $\begin{array}{l}\text { shemi } \\
\text { (good }\end{array}$ & - & $\begin{array}{l}\text { shemivene } \\
\text { better }\end{array}$ & $\begin{array}{l}\text { - shemivha } \\
\text { best) }\end{array}$ \\
\hline vbemi & - & vbemivene & - vbemivha \\
\hline (bad & - & worse & worst) \\
\hline $\begin{array}{l}\text { bu } \\
\text { (many }\end{array}$ & - & $\begin{array}{l}\text { buvene } \\
\text { more }\end{array}$ & $\begin{array}{l}\text { - buvha } \\
\text { most) }\end{array}$ \\
\hline kheke & - & khekevene & - khekevha \\
\hline
\end{tabular}


(little less least)

Okpameri language has adjectival word-order in an utterance. The headword is usually post modified unlike English where adjectives are usually pre-modified. The adjectival word-order in Okpameri is not as complex as that of English. Two modifiers are usually used to modify the headword. Consider:

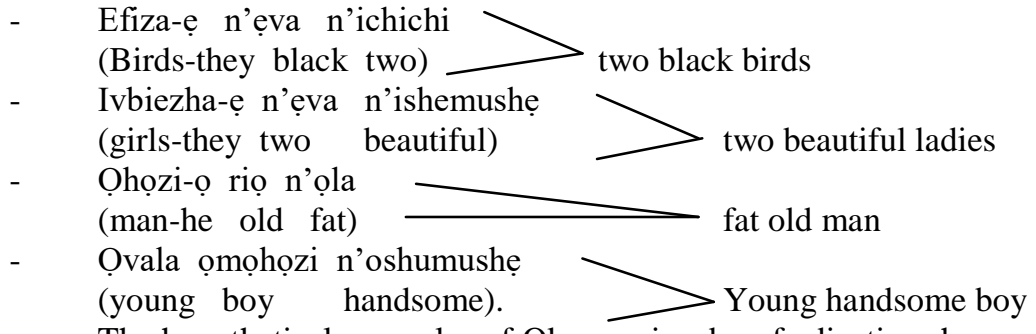

The hypothetical examples of Okpameri order of adjectives have revealed the uniqueness in the headword and its modifiers. The headword is sometimes followed immediately by its pronoun. The researchers simply refer to such pronouns as "headword tag", while the letter representing sound that comes before the modifiers as prefix is referred to as "word-particle".

Having briefly examined the structures and functions of adjectives of the two languages, it is expedient to also briefly examine some sociolinguistic concepts like "bilingualism" and "linguistic interference as they sometimes constitute learning problem to ESL learners.

Bilingualism: Akindele and Adegbite (2005), describe Bilingualism as the use of two languages either by an individual or a speech community. By implication, Bilingualism gives room for the co-existence of two languages in the repertoire of an individual or a speech community. It could be submitted therefore that Bilingualism is the ability an individual has to produce meaningful utterances in the other language in a bilingual speech community. However, such an individual could be deficient in either of the two languages. The resultant effect of this could be technically referred to as Linguistic Error. Linguistic Error occurs when a bilingual unconsciously transfers the structure of the language that he is more proficient in to the language he is less proficient in.

Linguistic Interference: Omolaiye (2017) identifies Linguistic Interference as those instances of deviation from the norms of either language that occurs in the speech of a language user as a result of familiarity with more than one language. This is why Weinreich (1953) describes Linguistic Interference as the rearrangement of patterns that result from the introduction of foreign elements into the more highly-structured domains of language. In view of this, it is essential to do a comparative study where two languages (as in the case of English and Okpameri) co-exist so as to examine their area(s) of similarities and differences as this will enable an analyst or contrastivist predict the likely problem area(s) for the natives in the course of using the target language.

\section{MEthodology}

In generating Okpameri adjectives for analysis, two methods were adopted viz-a-viz oral interview and participatory observation. Secondary data were got from the works of Omolaiye (2013, 2015, 2016 and 2017). Twenty informants including males and females who are between the age bracket of 60 and 85 years and are also native speakers of Okpameri language were interviewed. The researchers' intuitive knowledge in Okpameri language enhanced participatory observation in linguistic exchanges that involve the use of Okpameri adjectives in a natural setting. As in the case of the English data, the researchers made use of relevant literature obtained from library, relevant English grammar texts and internet sources.

It is also important to look at the theoretical framework that will actually enhance our data analysis. Hence, the study is predicated on Contrastive Analysis as it is relevant to the comparative study of two languages. According to Di Pieto (1971) and James (1980), Modern Contrastive Linguists began with Lado's "Linguistics Across culture" in 1957. And by expansion, Lado's work was given impetus by earlier works of Weinreinch (1953) on the linguistic integration of immigrants in the united state of America (see Ojo, 1996, Omolaiye, 2013).

Contractive Analysis remains an influential construct in the field of second language acquisition. It is a linguistic tool used in knowing what are needed and what that are not needed in the context of Target Language (TL). CA is also an instrument used to identify whether two languages have something in common thereby identifying the similarities and differences of the two languages under study in order to expand and expound the frontier of language universality. James (1980:3) describes Contrastive Analysis as a linguistic enterprise aimed at producing inverted (i.e contrastive) two valued typologies in that, a pair of language is found on the assumption that language can be compared.

Routledge Encyclopedia of Language Teaching (1990:14) makes distinction between Theoretical and Applied CA. While Theoretical CA is concerned with the production of extensive account of the differences between the languages contrasted, Applied CA is concerned with a reliable prediction of the learner's difficulties (James, 1980:181). Contrastive Analysis like Error Analysis and Translation Theory is a form of intelingua study in which two languages are involved. In view of this, CA therefore deals with issues that arise in the process of leaning a second language after the bases of the first language $\left(\mathrm{L}_{1}\right)$ has been acquired. The pre-occupation of Contrastive Linguistics in its comparison of language is to provide the methods for language teaching. By so doing, features of language structure revealed in CA 
may suggest modification and will certainly be further modified in the light of future experiences, thereby improving on finer grading of learners' difficulties.

The major concern of CA therefore, is to do a descriptive study individually of the two languages under study and subsequently juxtapose them for areas of similarities and differences as this will enable the contrastivist predict difficulties and perhaps postulate a hierarchy of difficulties hoping that this would help in improving on teaching methodology. This will serve as a tool in solving learning problems emanating from some of the perceived difficulties of learning the English adjectives and expressing the Okpameri terms in English.

CA hypothesis therefore claims that the major barrier to second language acquisition is the interference of first language system with the second language system in that, a scientific structural analysis of the two languages in question would yield a taxonomy of linguistic contrast between them which in turn would enable linguists and language teachers predict the problem area(s) a learner would encounter. Lado (1957:267) asserts that where the language patterns are similar in the two languages under study, learners of the TL would find language relatively easy, because the inputs they are now exposed to are not new to them. On the other hand, where the language patterns of the TL and the MT differ, the learning of the TL would be relatively difficult. The difficulties predicted by CA cannot be properly taken care of without recourse to Error Analysis (EA) as Error Analysis deals with the actual errors committed by the ESL learners. In the light of this, it is not out of place to mention here that CA and EA are related in that no contrastivist has ever really predicted solely on the basis of the CA, but has to be relied on his or on teacher's knowledge of errors already committed. James (1980) corroborates this when he claims that CA is always prognostic while EA is diagnostic. Thus, $\mathrm{CA}$ and EA are linguistic approaches used to account for $\mathrm{L}_{1}$ learning problem(s).

\section{RESULTS AND ANALYSIS}

For the purpose of clarity of data presentation, adjectives are classified as pre/post modifying adjectives, predicative adjective, degree of adjective and order of adjective. English, being the target language, is contrasted with Okpameri using samples of the data of the two languages. Ibillo variant of Okpameri language is adopted for analyzing Okpameri data. The analysis begins with pre/post modifying adjective. The adjectives of the two languages under study are underlined in the nominal group or sentences being contrasted. It must be mentioned here that, at the level of order of adjective, only nominal group containing two modifiers are analyzed as the structure of Okpameri adjective does not often give room for more than two adjectives modifying one headword in a nominal group.

\section{Pre/Post Modifying Adjectives}

The following (proper, nominal, descriptive verbal, demonstrative attributive, possessive, interrogative, emphatic, the articles, determinant, numerical adjectives etc.) are classified as pre/post modifying adjectives because they follow almost immediately the headwords they modify. Some of the sample data gathered are presented below:

TABLE 1

THE PRE/POST MODIFYING ADJECTIVES

\begin{tabular}{|l|l|l|}
\hline S/N & \multicolumn{1}{|c|}{ English } & \multicolumn{1}{c|}{ Okpameri } \\
\hline 1. & Good child & Omọ n'oshemi \\
2. & First person & Onyo okenike \\
3. & Two children & Ivbia n’eva \\
4. & Young goat & Uvhazi izili \\
5. & Young person & Omọ Ovala \\
6. & That house & Ukpo mọ \\
7. & Which book? & Mhẹmẹ kpa \\
8. & Only me & Utousha n'asah \\
9. & Forbidden fruit & Ineneh avboh \\
10. & His name & Onyo Inigeria \\
11. & Nigerian citizen & Itenugu Inigeria \\
12. & Nigeria police &
\end{tabular}

\section{Contrastive Statement}

Some of the samples of the data presented have revealed the similarities and the differences of English and Okpameri with respect to how adjectives of the two languages under study modify the headword in a nominal group or noun phrase. It is obvious that the two languages (English and Okpameri) have modifying adjectives. However, there is difference in the area of grammatical environment in which the headword is modified. While English adjectives usually pre-modify the headwords, Okpameri adjectives often post modify the headword except uvhazi (young) that premodifies the headword izili (goat) in a nominal group.

It must be mentioned here that English adjectives also post modify headwords. However, few adjectives perform this function. Some of these examples are "election proper", "money available", "the president elect", "the house ablaze" etc

While the adjective "young" is consistent as revealed in (4), and (5), its translation equivalent in Okpameri reveals non-consistence. Another difference between English and Okpameri adjective structure and usage is at the area of morphological realization. While the noun "Nigeria" is suffixed to perform the function of an adjective in a nominal group in English as revealed in (11), this derivational morpheme is absent in the Okpameri adjective. Similarly, the suffix 'en' attached to the verb 'forbid' in (9) to perform the function of an adjective is alien to Okpameri adjective as 
Okpameri resorts to using nominal adjective to function as a modifier. While English differentiates between its proper adjective and nominal adjective, as revealed in (11) and (12), Okpameri resort to using nominal adjective as both proper and nominal adjectives.

From the table above, the Okpameri learners of English, may be confronted with how to use proper noun as adjective in a sentence. They may tend to say "America cars" instead of "American cars". They may also render expression like "forbidden fruit" as "forbid fruit" as Okpameri verbs are not inflected to perform the function of adjective.

\section{Predicative Adjectives}

Some adjectives are classified as predictive adjectives because of the function they perform in a sentence. Jimoh (2009) describes Predicative Adjectives as adjectives used to limit or complete the meaning of the verb in a sentence. These adjectives usually come immediately after a be-verb or linking verb. This verb is said to have linked the adjective with the modified subject. Some grammarians like Farinde, and Ojo (1998), Halliday (1961), Osisanwo (1996), Quick, et. Al (1973), Ojo (2011) etc. describe predicative adjectives as "subject-complement, or "complement intensive". The data of this adjective type are presented thus:

\section{Predicative Adjective}

\begin{tabular}{|l|l|l|}
\hline \multicolumn{1}{|c|}{ English } & \multicolumn{1}{c|}{ TABLE 2} \\
\hline S/N & \multicolumn{1}{|c|}{ Okpameri } \\
\hline 1. & Ojo is good. & Ojo-o shemi. \\
2. & She is beautiful. & O shemilushẹ. \\
3. & Joy is tall. & Joy-o shẹhẹ. \\
4. & He is handsome. & O shemilushẹ. \\
5. & It is correct. & E bozoh. \\
6. & It tastes good. & I nemah. \\
7. & He is happy. & Egua vbọ l'enemah. \\
8. & She is old. & O ri l'orio. \\
9. & Ayo is lazy. & Ayo-o ri l'avbua. \\
10. & God is $\underline{\text { mighty. }}$ & Oshọkogi-Ö khoi. \\
11. & Sunday is intelligent. & Sunday-o nezugueh. \\
12. & Ibillo is popular. & Ibillo-I whienawa. \\
\hline
\end{tabular}

\section{Contrastive Statement}

The sentences of the two languages presented have revealed the Predicative Adjectives as both languages have predicative adjectives. However, there is difference at the level of structure. While the English verbs are followed immediately by the adjectives, Okpameri subjects of the sentence are followed by predicative adjective as Okpameri linking verbs are often lopped with the predicative adjectives. This uniqueness (lopping of verb with adjective) is also peculiar to Yoruba language as we have in the expression like "O dara" (it is good). "O" is the subject pronoun while "dara" is a predicative adjective in which case, the verb "is" is lopped with the adjective.

Another area of difference is adjectival gender sensitivity. While the complement intensives of "he and "she" as revealed in (2), and (4), are "beautiful" and "handsome" respectively, there is no distinction of this in Okpameri predicative adjective as Okpameri resorts to using un-gender. The Okpameri word "ri" in (8) and (9) is an active verb which its equivalent in English in "doing" is thus followed by nouns (l'orio and l'avbua) in Okpameri grammatical context. Structurally, "l'orio" and "l'avbua" are nouns but function as predicative adjectives.

The perceived problem the Okpameri learners of English as a second language may likely face is the use of "beautiful" and "handsome". The Okpameri speaker of English may tend to use these predicative adjectives indiscriminately as Okpameri language does not distinguish between feminine and masculine predicative adjectival gender. In the same manner, the Okpameri ESL learners may find it difficult to use the appropriate linking verbs since such verbs (is, are, be, was etc.) are often lopped with the predicative adjectives in Okpameri language. They may lend to render expression like "The boys is or are good" instead of "the boys are good".

\section{Degree of Adjectives}

Degree of adjectives are also referred to as comparison of adjectives as adjectives are expressed in terms of grading in which comparative and superlative are formed by attaching inflectional morphemes to the root-word as suffix. Three degrees of adjective are identified to include positive, comparative and superlative. Adjective is positive when it is used to talk about quality or a person, place or thing. Comparative adjective is used to compare two persons, things or qualities, while the superlative form has to do with the comparison of more than two persons or things.

The data are hence presented: 
TABLE 3

\begin{tabular}{|c|c|c|c|c|c|c|}
\hline & \multicolumn{2}{|c|}{ Positive } & \multicolumn{2}{|c|}{ Comparative } & \multicolumn{2}{|c|}{ Superlative } \\
\hline & English & Okpameri & English & Okpameri & English & Okpameri \\
\hline 1. & Big & Khọi & Bigger & Khọivene & Biggest & Khoivha \\
\hline 2. & Small & Kheke & Smaller & Khekevene & Smallest & Khekevha \\
\hline 3. & Fat & $\mathrm{L}$ & Faller & Lavene & Fattest & Lavha \\
\hline 4. & Loud & Fiea & Louder & Fieavene & Loudest & Fieavha \\
\hline 5. & Wide & Vboti & Wider & Vbotivene & Widest & Vbotivha \\
\hline 6. & Good & Shemi & Better & Shemivene & Best & Shemivha \\
\hline 7. & Bad & Vbhemi & Worse & Vbhemivene & Worst & Vbhemivha \\
\hline 8. & Many & $\mathrm{Bu}$ & More & Buvẹne & Most & Buvha \\
\hline 9. & Little & Kheke & Less & Khekevenẹ & Least & Khekevha \\
\hline 10. & Beautiful & Shemulushẹ & More beautiful & Shemulushẹvene & Most beautiful & Shemulushẹvha \\
\hline 11. & Heavy & Khọhi & Heavier & Khohvene & Heaviest & Khohvha \\
\hline 12. & Happy & Tanah & Happier & Tanahvene & Happiest & Tanahvene \\
\hline
\end{tabular}

\section{Contrastive Statement}

The table has revealed the similarities between the two languages under study. There is similarity at the level of suffix attached to the root-word to form comparative and superlative adjectives. The table has revealed "er" and "est" morphemes of the two languages compared. Both languages are inflected for comparative and superlative adjectives. As earlier mentioned, the morphemes are attached to the root-words as suffix. The difference between English and Okpameri is in the area of regular adjective. While the Okpameri language has regular adjectives (like shemishemivene-shemivha), some of the English words do not follow this trend. Examples of such words as presented in the table are "good"- "better"- "best", "bad" - "worse" - "worst".

Another difference between English and Okpameri adjective is the area of multi-syllabic adjective as some of the multi-syllabic adjectives in English take "more" and "most" as pre-modifiers of theirs adjectives to indicate comparative and superlative forms. This is evident in (10) where "more" and "most" pre-modify "beautiful" to form comparative and superlative adjectives. This is not so in Okpameri adjectives.

Okpameri learners of English may be confronted with the appropriate use of "good" and "bad" in comparative and superlative respectively. They may tend to say "good" - "gooder" - "goodest", or "bad" - "bader" - "badest".

\section{Order of Adjective}

When two or more adjectives are used to pre-modify the headword, they are arranged according to the dictates of the language that owns the modifiers. In other words, pre-modifier do not follow one another arbitrarily. The data gathered has revealed this claim. Some of the samples are therefore presented below:

\begin{tabular}{|l|l|l|}
\hline S/N & \multicolumn{1}{|c|}{ English } & \multicolumn{1}{c|}{ Okpameri } \\
\hline 1. & Beautiful young lady & Ovala omuvhizi n'oshemushe \\
2. & Two big goats & Izizi n'eva n'ekhoi \\
3. & White dried maize & Ugbado n'ufu n'uvhola \\
4. & Sharp flat cutlass & Egbeleh n'emua n'apekete \\
5. & Clean big place & Asha n'afuema n'akhoi \\
6. & Three ugly women & Ezha m'enesa n'ifiasa \\
7. & Two black birds & Efiza n'eva n'ichichi \\
8. & My large land & Eke mẹ n'ekhoi \\
9. & Tall Nigerian soldier & Ishoja inigiria n'oshe \\
10. & Clean bottle water & Amẹh ukpalava n'evia \\
11. & That big house & Ukpo n'ukhoi umoh \\
\hline
\end{tabular}

\section{Contrastive Statement}

From the table above, the two languages have order of adjective. However, there is difference in the word order as evident in the table. While English adjectives usually pre-modify the headword, this is not so in Okpameri as Okpameri adjectives usually post modify the headword, except the adjective ovala (young) that pre-modifies the headword omuvhizi (lady). Even then, the adjective n'ọshemushẹ (beautiful) still post modifies the headword. By implication, English adjectival pre-modification is consistent while that of Okpameri is not.

The likely problem the Okpameri learners of English may be confronted with is how to identify the headword in a nominal group since the order of adjective of the two languages under study is different. Proper noun (like Nigerian) used as adjective may also pose challenge to Okpameri ESL learners since Okpameri language does not distinguish between proper noun used as adjective and noun used a nominal adjective.

\section{DISCUSSION}

Investigating structural variation of adjectives in English and Okpameri has, indeed, revealed areas of similarities and differences of the two languages. The similarities have revealed grammar universality. As evident in English and Okpameri languages, every language has words used to give more information about a noun. The major function of adjectives, therefore, is to pre/post modify a noun. Adjectives also perform the function of subject-complement in a given sentence. Grammarians refer to such adjectives as subject-complement or complement intensive. However, the 
grammatical structure of adjective of every language differs. This difference is usually a function of culture (see Ojo, 1996). This is because the lexis and of course, adjective of every language, is culture-bound. This also buttresses the assertion of Sapir-Worf Hypothesis (1921) that each language creates its own world and therefore its own meaning. Thus, culture plays significant roles in language structure. These are revealed in the two languages examined.

With respect to headword modification, English adjectives usually pre-modify the headword while Okpameri adjectives often post modify the headword of any given nominal group or noun phrase, except uvhazi (young) and ovala (young) where the adjectives pre-modify the headwords. While some nouns and verbs are suffixed to perform the function of adjective, this is not so in Okpameri as such morphological marking is alien to the grammar of Okpameri. Okpameri language rather resorts to using noun to perform the function of an adjective in a nominal group. In other words, Okpameri does not distinguish between proper noun and nominal noun used as adjective. The problem that Okpameri language users of English may likely face is how to use proper noun as adjective in a nominal group as they may tends to say "America cars" instead of "American cars". Okpameri ESL learners may also tend to render this expression thus: "forbid fruit" instead of "forbidden fruit".

The two languages (English and Okpameri) have predicative adjectives. The study has, however, revealed area of difference. While English predicative adjectives follow almost immediately the linking verbs, Okpameri often lopped the linking verb with the predicative adjective. The study has also revealed predicative adjectival gender sensitivity in English as against Okpameri language that does not distinguish between gender predicative adjectives. For instance, shemilushẹ is zero gender in that the adjective-"shemilushẹ" is used as uni-gender, while the English masculine and feminine subject complements are handsome and beautiful respectively. In view of this difference, "beautiful" and "handsome" may likely pose problem to Okpameri learners and users of English adjectives as they may tend using these gender adjectives interchangeably.

As in the case of degree of adjective, the two languages under study have degree of adjective. In other words, English and Okpameri have "positive", "comparative" and "superlative" adjectives and suffixes are attached to the root-words to form comparative and superlative adjectives. However, there is difference in the area of regular adjectives. While Okpameri language has regular adjectives as revealed in table 4, some of the English adjectives do not follow this trend.

Another difference between the two languages under study is in the area of multi-syllabic adjectives. Some of the English multi-syllabic words are usually pre-modified with words like "more" and "most" to have comparative and superlative adjectives. This is not so in the grammar of Okpameri. Hence, Okpameri learners of English may find it difficult to appropriately use the comparative and superlative adjectives of "good" and "bad" as they may resorts to rendering these expressions thus: "good" - "gooder" - "goodest" or "bad" - "bader" - "badest" instead of "goodbetter- best", "bad - worse - worst". The learners may also say "beautiful - beautifier, bueatifuest" instead of "beautiful - more beautiful - most beautiful".

The predictive problem is that, the Okpameri learners of English may sometimes find it difficult to locate the headword in a given nominal group because of the structural differences of adjectives in English and Okpameri. Okpameri ESL learners may also be confronted with the correct usage of a proper noun as a pre-modifier in a nominal group since Okpameri language does not distinguish between proper noun used as adjective and noun used as nominal adjective. An Okpameri speaker of English may say "Nigerian police" instead of "Nigeria Police".

In view of the $\mathrm{CA}$ hypothesis, the two languages under study have adjectives (pre/post modifiers, predicative adjectives, degree of adjective and order of adjectives). The two languages have revealed grammar universality. However, adjectives of the two languages differ in terms of structure and gender sensitivity. For instance, while English modifiers are usually used to pre-modify the headword, Okpameri modifiers are often used to post-modify the headword. Also, while English predicative adjectives - beautiful and handsome are gender sensitive, Okpameri predicative adjective "shemilushe" is used as zero gender or uni-gender in Okpameri nominal group. Thus, Okpameri ESL learners may be confronted with the appropriate use of English predicative adjective that is gender sensitive. Also, Okpameri learners of English as a second language may be confronted with the appropriate use of gender pre-modifiers like "his" and "her". This study therefore suggests that language teachers, particularly, the English language experts should concentrate more on the areas of differences in the teaching and learning of the English adjectives.

Investigating structural variation of adjectives in English and Okpameri has revealed some implications for the teaching and learning of English as a second language. Considering the fact that languages come in contact (as in the case of English and Okpameri), teaching and learning of ESL should be given due consideration. As a result, the following among others are highlighted thus:

As a matter of fact, Okpameri ESL learners should be exposed to the grammar of the two languages under study, in that the grammatical structure or feature of any language is usually characterized by the culture of the language. Therefore, learners should be exposed to the culture of the two languages because the lexical items of a particular language are regarded as carriers of the culture that produces the language. Emphasis should be on the literature component of English and Okpameri language teaching programmes because literature is the practical use of language. Language teachers should be encouraged to also teach the aspect of literature in our school system.

The teaching of adjectives should be handled using systematic approach. That is, language experts should be acquainted with full knowledge of adjectival structures of the two languages as this will enable teaching and learning to be more effective and productive. Also, standard, adequate and relevant instructional materials as well as conducive 
environment for learning should be made available and accessible as these will enhance efficiency and effectiveness in the teaching of English adjectives. English language curriculum at every level of education should be made dynamic as this will enable language teachers develop new approaches in teaching adjectives.

Finally, the study has revealed variations in the way different language communities are caused by their language to engage with the world in distinctive manner. This is evident in this research. Adjectives are culture-bound and a good understanding of them demands familiarity with the cultures that produce them. Hence, adjectives of the two languages under study should be handled by language experts in the context of ESL as this would aid learners in studying the adjectives of the two languages.

\section{CONCLUSION}

Contrastivists usually embark on comparing two languages (particularly, the indigenous and the target languages) in order to provide the methods or approaches for language teaching. Features of the language structure revealed in CA may suggest modifications and this will certainly be further modified in the light of future experience as it may enhance a finer grading of learners' learning problem(s). Thus, this paper has revealed the variations in the structure and usage of the two languages under study. These variations have reflected the culturally important features of how adjectives are used to enhance grammaticality. Hence, the acknowledgements of universal grammatical features are internal to the culture in which it operates and its usage has reflected on those variations that are important to its culture.

Since adjectives are more culture-bound and a good understanding of them demands familiarity with the culture that produces them, it is therefore advised that Okpameri speakers and users of English should be exposed to the similarities and differences of English and Okpameri adjectives as this will enable them (Okpameri ESL learners) cope with the likely problems identified in the findings. As a matter of urgency, language teachers should come up with practical demonstration of these adjectives in the second language being learnt. In the light of this, dynamic and innovativeness on the part of the language experts are called for in order to make use of adequate teaching and learning materials. Consequently, the perceived difficulties of learning the English adjectives and expressing the Okpameri adjectives in English will be minimized.

\section{REFERENCES}

[1] Adegbite, W. \& Akindele, F. (2005). Sociology and Politic of English in Nigerian: An Introduction, Ile-Ife Obafemi Awolowo University Press.

[2] Ashaolu, A. O. (1993). Use of English and Functional Communication. Ado: Ekiti Petae Educational Publishers.

[3] Di Pietro, J. (1971). Language Structures in Contact. Massachussetts: Newbury House.

[4] Ekharo, T., Aliu, G. \& Akanji, J. (2007). The history of Somorika. Lagos: Dee Honour Company.

[5] Elugbe, B. (1989). Comparative Edoid: Phonology and Lexicon. Delta Series. No 6. University of Port-Harcourt Press.

[6] Farinde, R. \& Ogunsiji, Y. (2010). Analytical Linguistics. Ago-Iwoye: Olabisi Onabajo University Press.

[7] Farinde, R. \& Ojo, J. (1998). The grammatical structures of English: An illustrative approach. Ondo. Patrick Ade Press.

[8] Greenberg, J. (1978). Universals of Human Languages. Standard University Press, Stanford, Califonia.

[9] Hakeem, B. C. (2003). A culture history of the uneme from the earliest time to 1962. Lagos: The book company Ltd.

[10] Halliday, M. A. K. (1961). Categories of the Theory of Grammar. Word. 17(3). Pp. 241-92. Reprinted in full in on Grammar. Vol. 1 of the collected works of M.A.K Halliday: London and New York: Continuum.

[11] James, C. (1980). Contrastive Analysis. London: Longman.

[12] Jimoh, R. (2010). A Description Survey of the English Grammar. Ibadan. Alafas Nigeria Company.

[13] Lado, R. (157). Language teaching: A Scientific Approach. New York: Mc GrawHill.

[14] Murphy, J. D. (2007). Contemporary English Grammar, Lagos: Book Master Publishers.

[15] Ogundipe, P. A., Eckersley, C. E. \& Macaulay, M. (1983). Brighter Grammar Book 3. England: Pearson Education Limited.

[16] Ojo, J. O. (1996). A Contrastive Lexicology of Six Semantic Fields of English and Yoruba. Unpublished M. A. dissertation: University of Ibadan.

[17] Ojo, J. O. (2008). "A Contrastive Analysis of Tense, Aspect and Modality in English and Yoruba" Unpublished Ph. D Thesis: University of Ibadan.

[18] Ojo, J. O. (2011). “A Contemporary Functional Grammar of English”. Ago-Iwoye Olabisi Onabaja University Press.

[19] Omolaiye, H. O. (2013). A Contrastive Lexicology of Six Semantic Fields of English and Okpameri. Unpublished M. A. Dissertation. University of Ibadan.

[20] Omolaiye, H. O. (2015). Problems in the Syntactic Usage of Tense and Aspect in the Written Composition of Okpameri Secondary School Learners of English, in J. O. Ojo (eds). Journal of School Languages, Adeyemi College of Education, Ondo. Vol. 7, Pp. 227-257.

[21] Omolaiye, H. O. (2017). A Lexico-Semantic study of English and Okpameri Musical and Kitchen Terms: In J. O. (eds) Global perspective on English, Literature and Communication, School of Languages, Adeyemi College of Education, Ondo. Vol. 8, Pp. 222-232.

[22] Omolaiye, H. O. (2017). A Comparative Study of Lexico-Semantics of Standard British English and Nigerian English: In J. O. Ojo et. Al (eds) Journal of the School of Language, Adeyemi College of Education, Ondo. Pp. 71-79.

[23] Osisanwo, W. (1996). "Systemic Grammar as model of Grammatical Description: An Evaluation" in Ondo Journal of Arts and Social Sciences (OJASS) 1.1 1996, 1-19. 
[24] Oyelekan, C. O. (2002). Elements of Grammar I in Oluga et. Al. (ed) Essentials of use of English. A Pragmatic and Comprehensive Approach. Osogbo: Supreme Star Press.

[25] Quirk, R. and Greenbaum, S. (2002). A University Grammar of English: London. Rouledge Encyclopaedia of Language Teaching. 1990 edition.

[26] Sapir, E. (1921). Language: New York: Harcourt, Brace \& World.

[27] Weinreich, U. (1953). Languages in Contact. The Hague: Mouton.

Raifu O. Farinde was born in Erin- Osun, Osun State, Nigeria on March 4, 1970. He attended Adeyemi College of Education, Ondo, Nigeria, between 1988 and 1992 for his Bachelor's Degree in English Education. He obtained his M.A in English Language from the University of Ibadan, Nigeria in 1998. He also bagged his PhD in Linguistics and English Language from the University of Wales, Bangor, United Kingdom now Bangor University, Bangor, United Kingdom in 2007.

He currently lectures at the Department of English and Literary studies, Federal University Oye-Ekiti, Nigeria. He has worked at Adeyemi College of Education, Ondo, Nigeria and he left there as a Chief Lecturer. At present, he is a Senior Lecturer at the Federal University Oye-Ekiti, Nigeria. Among his published works includes Forensic Linguistics: An introduction to the Study of Language and the Law Allemagne, Germany: LIMCOM GMBH, 2009. He also co-authored with Dr. Ojo J.O. Introduction to Sociolinguistics Ondo, Nigeria: Lektay Publishers, 2005. Furthermore, He co-authored with Dr. Yemi Ogunsiji Analytical Linguistics Ago-Iwoye, Nigeria: Olabisi Onabanjo University Press. 2010. His research interests include Pragmatics, Forensic Linguistics, Discourse Analysis, Sociolinguistics and Systemic Functional Grammar.

Dr. Farinde is a member of several learned societies some of which are British Association of Applied Linguistics (BAAL), Linguistic society of America (LSA), Nigeria English Studies Association (NESA) and English Language teachers Association of Nigeria (ELTAN). He is a recipient of Ford Foundation International Fellowship for PhD organized by the Institute of International Education (IIE) New York between 2003 and 2006. Among his awards, honours and distinctions are Certificate of Achievement, UK, 2005, Certificate of Completion, 2004, Certificate of Recognition, 2013.

Happy O. Omolaiye was born in Ibilo, Edo state Nigeria on April 4, 1974. He attended Adeyemi College of Education, Ondo, Nigeria, between 2004 and 2009 for his Bachelor's Degree in English Education. He obtained his M.A in English language from the University of Ibadan, Nigeria in 2003.

He currently lectures at the Department of General Studies, Federal Polytechnic, Ile -Oluji, Nigeria. He had worked in private secondary schools in Ondo State, Nigeria, as a teacher of English language. At present, he is a lecturer 1 (L1) at the Federal Polytechnic, Ile - oluji, Nigeria. Among his published works include: An Investigation of problems in the Syntactic usage of Tense and Aspect among Okpameri secondary school Learners of English, Ondo, Nigeria, School of Languages Adeyemi College of Education 2015, Lexico-Semantic Study of English and Okpameri Musical and Kitchen Terms Ondo, Nigeria, School of Languages, Adeyemi College of Education, 2016, Using Linguistic Signals to Express Corrupt Practices on Nigerian Campuses, Ede, Nigeria, Department of General Studies, 2019. His research interests include Contrastive Linguistics, Systemic Functional Grammar, Pragmatics and sociolinguistics.

Mr Omolaiye is a member of several learned societies some of which are National English Studies Association (NESA), National Association of Teachers of Language in Colleges of Education and Polytechnics in Nigeria (NATECEP) and Linguistics Association of Nigeria (LAN). He received New Age Leadership Skills for High Organizational Performance Certificate, 2018. 